\title{
Tonogenesis and tonal alternations in Khaling
}

\author{
Guillaume Jacques
}

October 20, 2016

Jacques, Guillaume. 2016e. Tonogenesis and tonal alternations in Khaling. In Enrique L. Palancar and Jean Léo Léonard (eds.), Tone and Inflection, 41-66. Berlin, New York: Mouton de Gruyter.

Abstract: In this paper, we present a historical account for the tonal alternations observed in the Khaling verbal system. We show that most of these alternations can be explained by two series of sound change. First, level and falling tones appeared in closed syllables with sonorant and obstruents codas respectively. Second, the loss of vowels in specific contexts lead to the development of additional falling tones. A residue of falling tones remain unaccounted for by the present reconstruction, but several hypotheses are proposed to explain their origin. Keywords: Tonogenesis, Syllable reduction, Obstruents, Kiranti, Khaling

\section{Introduction}

Khaling, ${ }^{1}$ like other Kiranti languages, has a very complex templatic verbal morphology (see for instance Bickel et al. 2007 and Jacques 2012). It is unique in the Kiranti subgroup however in having relatively recently innovated a tonal system. ${ }^{2}$

Tone in Khaling is not only phonemic in that it is used to distinguish between lexical minimal pairs, it also plays a critical role the structure of the verbal inflectional system of the language. Complex patterns of stem alternations involving vowel, consonant and tonal changes are observed in this language. These alternations are not correlated in isomorphic fashion with any morphosyntactic feature. The distribution of stems ${ }^{3}$ (and of tonal

\footnotetext{
${ }^{1}$ Khaling is spoken by around 15000 speakers in Solukhumbu district, Nepal, see Figure

${ }^{2}$ Tonogenesis and most vowel changes postdate the start of Nepali influence in the eighteenth century, as will be shown in section 4.1.1.

${ }^{3}$ In the present paper, we use the term 'root' to designate abstract forms from which the entire paradigms can be mechanically generated, and the term 'stem' to refer to the part of the inflected verbs remaining once prefixes and suffixes have been removed, in other words, roots to which morphophonemic changes have been applied.
} 



Figure 1: Map of Kiranti languages (from Opgenort 2011)

alternations) in the Khaling verbal system is influenced by transitivity, person and number of one or two arguments, tense (past vs non-past) in an intricate way. The complete list of conjugation classes, as well as a computational model to automatically generate them is provided in Jacques et al. (2012). The conjugation classes with the greatest number of stems has up to ten of them, while those with the fewest number of stems only have two (but such classes are very limited).

Table 1 illustrates some typical examples of stem alternations. All the forms in the table comprise a stem followed by one unstressed short vowel suffix (which has no tonal contrast). These data show that while in some verb conjugation classes the tone is constant in all stems (for instance, in the case of the verb 'jump' we have level tone, indicated by a macron, in all forms), in most conjugation classes we observe alternations between falling tone (marked with a retroflex accent) and level tone (with a macron, see the conjugation of 'touch') or between falling tone and short vowel syllables where the tonal contrast is neutralized ('go' and 'hit').

Table 1 also illustrates the fact that tonal alternations in Khaling are not completely independent from vowel and final consonant alternations: in the case of the verb 'touch' for instance, we see that the level tone is correlated 
with the stem final consonants $-j$ and $-t s$, while the falling tone appears in stems with final $-n$.

Table 1: Examples of tonal alternations in the Khaling verbal system

\begin{tabular}{|c|c|c|c|c|}
\hline Infinitive & Non-past 1DI & Non-Past 3PL & Past 3SG & Meaning \\
\hline$b^{h} O \overline{\jmath j}-n \mathcal{E}$ & $b^{h} \bar{\theta}: t s-i$ & $b^{h} O \hat{n} n-n u$ & $b^{h} O \hat{\jmath} n-t \varepsilon$ & touch (tr) \\
\hline tsō̄j-nE & $t s \bar{\theta}: t s-i$ & tsō̄j-nu & $t s \bar{\theta}: s-t \varepsilon$ & jump (intr) \\
\hline$k^{h} O \hat{\jmath ̂ n-n \mathcal{E}}$ & $k^{h} \theta t s-i$ & $k^{h} o \hat{\jmath} n-n u$ & $k^{h} \theta S-t \varepsilon$ & go (intr) \\
\hline roŝn-nE & rets-i & rê:t-nu & $r \hat{\theta}_{i}^{\prime}-t \varepsilon$ & hit (intr) \\
\hline
\end{tabular}

In addition, we observe that stem distribution and tonal alternation cannot be accounted for by a single factor. Walther et al. (2014) has shown that stem alternations is Khaling are better accounted for by a morphomic account, rather than in terms of transparent morphosyntactic features.

The apparent chaos of verb stem alternations in general, and the opacity of tonal alternations in particular, can however be partially accounted for by a historical account based on a combined application of the comparative method and of internal reconstruction. Most of the tonal alternations in Khaling can be straightforwardly explained as the mechanical result of two major sources of tonal contrasts: the transphonologization of stem final consonant contrasts into tonal contrasts, and the creation of falling tones following the loss of some final syllables.

Given the fact that tonal alternations are not completely independent from segmental changes in Khaling, it is necessary to opt for an approach that does not treat tones in isolation from vowel and consonants, and therefore part of the paper will provide the minimal quantity of information on segmental alternations and their origins that are necessary to make sense of the tonal alternations.

First, we describe Khaling synchronic phonology, including segmental inventories, phonotactic rules and tonal contrasts.

Second, we present a simplified picture of stem alternations in Khaling, ${ }^{4}$ and propose to reconstruct a stress pattern in pre-Khaling to account for vowel lengthening in some stem types. Although this section does not directly discuss tonal alternations in Khaling, it is a pre-requisite for the complete tonogenesis model elaborated in the following section.

Third, we provide a detailed account of tonogenesis in Khaling. Although a partial discussion of the origin of tones can be found in Michailovsky (1975), the present paper, based on more reliable and complete data, shows that tones in Khaling have more than one origin and describes for the first time the development of falling tones from simplification of disyllables. Some

\footnotetext{
${ }^{4}$ For reasons of space, since the present paper is focused on tone, this section is limited to the strict minimum necessary to follow the tonogenesis model. An exhaustive account of alternations can be found in Jacques et al. (2012).
} 
sound laws are demonstrated on the basis of data from nouns rather than verbs, to avoid circularity in the internal reconstruction of the verbal system.

Fourth, we show how the model of tonogenesis proposed in the previous section can account for most tonal alternations in the Khaling verbal system. Pre-Khaling as reconstructed in this model was more similar to other Kiranti languages in having a less elaborate system of stem alternation, and suprasegmentals were restricted to stress shifts.

Fifth, we point out the presence of a residue of forms which cannot be explained as the result of regular sound changes using the laws elaborated in the tonogenesis section. Several potential lines of explanation involving analogical leveling are explored.

\section{Synchronic phonology}

As shown in Jacques et al. (2012: 1098), Khaling has eighteen vowel phonemes (Table 2) and 27 consonant phonemes (Table 3). The only wordinitial clusters allowed are labial or velar stop +1 and $r$.

The consonant $c$ only appears as the first element of a word-internal cluster (as in $s e c ̧ k i$ 'we kill it'), never word-initially or word-finally. Only unvoiced obstruents and sonorants $-p,-t-k,-m,-n,-\eta,-r,-l,-s$ and $-j$ can occur as codas. Clusters involving two unvoiced stops or affricates (such as $p t, k t$ etc), as well as geminates (tt, $p p, k k$ and $t s t s)$, are realized with preaspiration when the preceding vowel is short. The diphthong or is treated as a unique phoneme.

Table 2: List of Khaling vowel phonemes

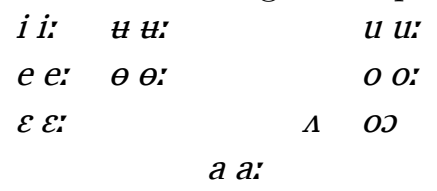

Table 3: List of Khaling consonantal phonemes

$\begin{array}{llllll}p & t & & t s & k & ? \\ p^{h} & t^{h} & & t s^{h} & k^{h} & \\ b & d & & d & g & \\ b^{h} & d^{h} & & d^{h} & g^{h} & \\ m & n & & & \eta & \\ & s & & c & & h \\ w & l & r & j & & \end{array}$

Khaling has a two-way tonal contrast on open syllables with long vowels or closed syllables with a sonorant coda. There is a high level tone (in- 
dicated by a macron $)^{5}$ and a falling tone (circumflex accent). A marginal contrast between surface low level and high level tone is also attested in a very restricted morphosyntactic environment (see below), but it is irrelevant for the description of verbal flexion and its phonological interpretation is deferred to future research.

The tonal contrast is neutralized on short and / or unstressed vowels. Note that in sonorant-final syllables, vowels are always long, and vowel length is not indicated as it is redundant. Table 4 illustrates possible tonal contrasts on monosyllables.

In polysyllables, only stressed syllables receive tone, and verbs and nouns alike only have one stressed syllable, except in the case of compound verbs, which are not discussed in this paper.

Table 4: Minimal pairs between level tone and falling tone in monosyllables

\begin{tabular}{ll}
\hline Form & Meaning \\
\hline$m \bar{\varepsilon} m$ & he \\
$m \hat{\varepsilon} m$ & mother \\
\hline$m \bar{\varepsilon}:$ & there \\
$m \hat{\varepsilon}:$ & (ideophone) rolling quickly \\
$m \varepsilon$ & that \\
\hline
\end{tabular}

In addition, a contrast between high level tone and a phonetically low tone is attested in the purposive construction with the locative suffix $-b i$ followed by a motion verb. Verbs whose root ends in a sonorant consonant $m, n, \eta, l$ or $r$ use the infinitive stem with level tone before the suffix $-b i$ as in example 1 . Root-final $-n$ changes to $-j$ in this context.

\section{(1) bîj $2 u-g^{h} a s \quad k \bar{\varepsilon} m-b i \quad k^{h} \theta S-t \varepsilon$}

cow 3SG.POSS-grass chew-LOC go-PST:3SG

'The cow went to chew the grass.'

Verbs with roots ending in obstruents use the nasalized infinitive stem (with final $-n$ or $-\eta$ respectively) with falling tone in this construction.

Noun and verb forms with falling tone remain unchanged as in 2: the free noun 'elk' $k \hat{\varepsilon} m$ has the same form as when occurring with the locative suffix.

(2) kêm-bi $k^{h} \theta S-t \varepsilon$

elk-LOC go-PST:3SG

'He went (to hunt) for the elk.'

\footnotetext{
${ }^{5}$ We opt for the macron rather than the acute accent for transcribing the level tone, as the acute accent is used in this paper for indicating stress in (non-tonal) pre-Khaling reconstruction, and we want to avoid confusion.
} 
Monosyllabic nouns with level tone, however, develop a low tone in the purposive construction when suffixed by -bi, as $k \bar{\varepsilon} m$ ' work $^{16}$ in example 3 .

(3) kغ̀m-bi $\quad k^{h} \Theta s-t \varepsilon$

work-LOC go-PST:3SG

'He went for his work.'

This highly restricted, syntactically determined low alternant of the level tone will not be considered further in the present paper, as its synchronic analysis in still unclear (in particular, it remains to be determined whether a similar contrast is found in other grammatical constructions), and it is not necessary to the analysis of the verbal morphology.

In the following, we show the origin of the tonal and length contrasts in Khaling. We point two origins for the falling tone: loss of obstruent codas and syllable reduction.

\section{Vowels and stress in pre-Khaling}

In this section, we provide a justification for the reconstructions used in the following sections, in particular for the stress patterns reconstructed for pre-Khaling, which have a direct effect on tonogenesis. Thus, this section mainly discusses vowel alternations from pre-Khaling (an earlier stage of Khaling closer to the common ancestor of Khaling and Dumi) to attested Khaling.

Previous scholarship on comparative proto-Kiranti (van Driem 1990, Michailovsky 1994, Starostin 1994-2000, Opgenort 2005) has focused on the reconstruction of proto-Kiranti initial consonants, but no work has been published on the vowel correspondences between Khaling and other Kiranti languages. In Khaling, as we will see, the evolution of vowels, codas and the development of tonal contrasts are closely related, so that an account of the basic vocalic sound laws is necessary for any further work on the topic.

Internal reconstruction suggests that the complex vowel system of Khaling was innovated from a simpler system, as can be ascertained from the vowel alternations in the verbal system and the complementary distributions between vowels and codas (Michailovsky 1975, Jacques et al. 2012).

As shown in Michailovsky (1975), Jacques et al. (2012) and Michailovsky (2012) using internal reconstruction, in both Khaling and Dumi, no more than five vowels have to be postulated in verbal roots. Complex morphophonological alternations yield all 18 vowels in different contexts. Table 5 illustrates the most important alternations: closed syllable verb stems can be classified into two major categories, weak and strong. Weak stems are found mainly in forms with vowel initial suffixes (the exceptions are shaded in Tables 7, 8 and 9 and discussed in section 5), and strong stems are

\footnotetext{
${ }^{6}$ Borrowed from Nepali kam.
} 
found with consonant-initial suffixes except in the case of verb stems with final clusters, which always have $t$ as second element (see the conjugation of CVCt roots in Table 9 and the discussion in section 3.4).

Table 5: Basic vowel alternations in the Khaling verb

\begin{tabular}{|c|c|c|c|c|c|}
\hline root vowel & $\begin{array}{l}\text { open } \\
\text { syllable }\end{array}$ & $\begin{array}{l}\text { velar } \\
\text { (strong) }\end{array}$ & $\begin{array}{l}\text { velar } \\
\text { (weak) }\end{array}$ & $\begin{array}{l}\text { non-velar } \\
\text { (strong) }\end{array}$ & $\begin{array}{l}\text { non-velar } \\
\text { (weak) }\end{array}$ \\
\hline$a$ & $\mathcal{E}$ & $a$ & $\Lambda$ & $\mathcal{E}$ & $\mathcal{E}$ \\
\hline$e$ & $e$ & $e$ & $e$ & $e$ & $e$ \\
\hline$i$ & $e$ & $\Lambda$ & $i$ & $\Lambda$ & $i$ \\
\hline$o$ & $\theta$ & $o$ & $\theta$ & OD & $\theta$ \\
\hline$u$ & 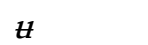 & $u$ & $t$ & $\Lambda$ & $\forall$ \\
\hline
\end{tabular}

Some stem forms (3SG:N.PST $\rightarrow 3 \mathrm{SG}$ and 3SG:N.PST $\rightarrow 3 \mathrm{SG}$ ) have a lengthened vowel (see Table 6), which we interpret as reflecting radical stress (vs suffixal stress) in pre-Khaling. Reconstructing stress for pre-Khaling has other important consequences, in particular for the Syllable Reduction Rule (section 4.2).

Table 6: Examples of basic vowel alternations in the Khaling verb

\begin{tabular}{|c|c|c|c|c|}
\hline Root & Meaning & $\begin{array}{l}\text { weak stem } \\
(1 \mathrm{DI}: \mathrm{N} . \mathrm{PST} \rightarrow 3 \mathrm{SG})\end{array}$ & $\begin{array}{l}\text { weak stem (lengthened) } \\
(3 \mathrm{SG}: \text { N.PST } \rightarrow 3 \mathrm{SG})\end{array}$ & $\begin{array}{l}\text { strong stem } \\
1 \text { PI:N.PST } \rightarrow 3 \mathrm{SG}\end{array}$ \\
\hline $\mid p^{h}$ rok $\mid$ & untie & $p^{h} r \theta k-i$ & $p^{h} r \bar{\theta}: g-t$ & $p^{h}$ rok-ki \\
\hline |lom $\mid$ & search & $l e m-i$ & lë:m-u & lō̄m-ki \\
\hline$|l o p|$ & catch & lep-i & $1 \bar{\theta}: b-u$ & lō̄p-ki \\
\hline
\end{tabular}

Tables 7, 8 and 9 illustrate the distribution of the stems in the Khaling verbal paradigms. Irregular cases, where a weak stem is found with a consonant-initial suffix, are shaded in grey. In addition to weak and strong stems, we also find lengthened weak stems in the transitive CVC paradigm.

The vowel alternations in Tables 5 and 6 suggest the existence of three (historical) vowel shifts in Khaling: fronting, lowering and backing. We provide an account of the Khaling vowel shifts on the basis of CVC intransitive and transitive paradigms in addition to some comparative data. Then, we discuss the case of verbs with roots in final clusters (which can only be CVCt) where additional minor sound laws have to be proposed. Finally, we tackle some additional issues concerning the Khaling vowel system in historical perspective.

\subsection{Fronting}

The non-front vowels $* a,{ }^{*} \boldsymbol{o}$ and $* u$ in pre-Khaling are fronted to $\mathcal{E}, \boldsymbol{\theta}$ and $\boldsymbol{u}$ respectively in open syllables. This shift occurred in open syllable roots, 
Table 7: Distribution of stems in the intransitive paradigm

\begin{tabular}{|c|c|c|c|c|c|c|}
\hline S & non-past & & past & & imperative & \\
\hline $1 \mathrm{~s}$ & strong- $\not \Lambda \Lambda$ & 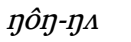 & weak- $\Lambda$ t $\Lambda$ & 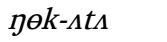 & & \\
\hline $1 \mathrm{DI}$ & weak- $i$ & $\eta j \theta k-i$ & weak-iti & nek-iti & & \\
\hline $1 \mathrm{DE}$ & weak- $\boldsymbol{u}$ & $\eta j \theta k-u$ & weak-utu & pek-utu & & \\
\hline 1PI & strong- $k i$ & nok-ki & strong-tiki & nok-tiki & & \\
\hline $1 \mathrm{PE}$ & strong-k $k$ & nok-kA & strong- $t \Lambda k \Lambda$ & nok-tıkı & & \\
\hline $2 \mathrm{~s}$ & Pi-strong & 2i-ந̂ô: & ?i-weak-tE & $P i-\eta j \theta k-t \varepsilon$ & weak-je & nok-je \\
\hline $2 \mathrm{D}$ & $2 i$-weak- $i$ & $2 i-\eta j \theta k-i$ & 2i-weak-iti & Pi-pek-iti & weak-ije & nok-ije \\
\hline $2 \mathrm{P}$ & $2 i$-strong-ni & Pi-ந刀ố-ni & 2i-weak-tcnu & 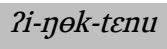 & weak-nuje & nok-nuje \\
\hline $3 \mathrm{~s}$ & strong & நô: & 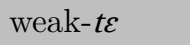 & $\eta j \theta k-t \varepsilon$ & & \\
\hline $3 \mathrm{D}$ & weak- $i$ & pek-i & weak-iti & nek-iti & & \\
\hline $3 \mathrm{P}$ & strong-nu & நô:-nu & weak-tenu & nөk-tenu & & \\
\hline
\end{tabular}

Table 8: Distribution of stems in the CVC transitive paradigm

\begin{tabular}{|c|c|c|c|c|c|c|}
\hline $\mathrm{A} \rightarrow \mathrm{P}$ & non-past & & past & & imperative & \\
\hline $1 \mathrm{~s} \rightarrow 3$ & weak- $u$ & $2 o b-u$ & weak-uts & Pob-utu & \multirow{7}{*}{$\begin{array}{l}\text { weak.length-e } \\
\text { weak-ije }\end{array}$} & \multirow{7}{*}{$\begin{array}{l}\text { Pē:b-e } \\
\text { Pop-ije }\end{array}$} \\
\hline $1 \mathrm{DI} \rightarrow 3$ & weak- $i$ & $2 \theta p-i$ & weak-iti & Pep-iti & & \\
\hline $1 \mathrm{DE} \rightarrow 3$ & weak- $u$ & 2өp-u & weak-utu & Pep-utu & & \\
\hline $1 \mathrm{PI} \rightarrow 3$ & strong-ki & 2osp-ki & strong-tiki & 2osp-tiki & & \\
\hline $1 \mathrm{PE} \rightarrow 3$ & strong- $k \Lambda$ & ?osp-ks & strong- $t_{\Lambda} k_{\Lambda}$ & ?osp-tıks & & \\
\hline $2 \mathrm{~s} \rightarrow 3$ & 2i-weak.length- $\boldsymbol{t}$ & $P i-P \bar{\theta}: b-u$ & Pi-weak.length- $t \varepsilon$ & 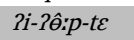 & & \\
\hline $2 \mathrm{D} \rightarrow 3$ & Pi-weak- $i$ & $2 i-P \theta p-i$ & 2i-weak-iti & 2i-Pep-iti & & \\
\hline $2 \mathrm{P} \rightarrow 3$ & $2 i$-strong-ni & 2i-2ô̂m-ni & ?i-weak-tcnu & 2i-Pep-tenu & weak-nuje & 2өp-nuje \\
\hline $3 \mathrm{~s} \rightarrow 3$ & weak.length- $t$ & $P \bar{\theta}: b-z$ & weak.length- $t \varepsilon$ & Pê:p-tE & & \\
\hline $3 \mathrm{D} \rightarrow 3$ & weak.length-su & P̂̂:p-su & weak.length-tesu & Pê:p-tesu & & \\
\hline $3 \mathrm{P} \rightarrow 3$ & weak.length-nu & ใê:p-nu & weak.length-tcnu & 2ô:p-tenu & & \\
\hline $1 \mathrm{~s} \rightarrow 2$ & strong-nE & 2ôิm-nE & strong-teni & 2ôิm-tcni & & \\
\hline $2 / 3 \mathrm{~s} \rightarrow 1 \mathrm{~s}$ & $i$-strong- $\not \Lambda$ & 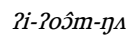 & $i$-weak- $\iota t \Lambda$ & 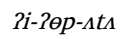 & weak-ıje & Pөp-ıje \\
\hline $3 \mathrm{~S} \rightarrow 1 \mathrm{PI}$ & $i$-strong- $k i$ & 2i-Poगp-ki & $i$-strong-tiki & 2i-Posp-tiki & strong-kıje & Posp-kıje \\
\hline
\end{tabular}

but also in weak stems, where (in pre-Khaling) suffixes are vowel-initial and the coda is resyllabified as the onset of the next syllable.

Thus for instance the proto-form *lóm- $u$ (search-3SG:N.PST $\rightarrow 3 \mathrm{SG}$ ) is resyllabified as *ló.mu and undergoes the shifts $* o \rightarrow \theta$ and $* u \rightarrow u$ to *ló.mu and the stress on the first syllable causes vowel lengthening to the attested form lē:mt 'he searches for it'.

This shift does not occur in regular velar final verbs with $|\mathrm{a}|$ vocalism such as the transitive verb $|k a k|$ 'peel', which has a weak stem in $\Lambda$ ( $k \wedge g-u$ 'I peel it') or $a:$ (kā:g- $\boldsymbol{t}$ 'He peels it') instead of expected $\mathcal{\varepsilon}$ and $\mathcal{\varepsilon}$ : Thus, the fronting shift was limited to rounded vowels when occurring before velars. ${ }^{7}$

Only one verb does not fit the pattern in Table $5:|j a l|$ 'strike', which

\footnotetext{
${ }^{7}$ The intransitive verb $\left|b^{h} a k\right|$ 'go (honorific)' (Jacques et al. 2012: 1115) presents the stem $/ b^{h} \mathcal{E} /$ in dual forms $\left(b^{h} \mathcal{E}-j i\right.$ go-N.PST:1PI) with irregular loss of the final $k$ showing the $a \rightarrow \mathcal{E}$ shift ( ${ }^{*} b^{h} \Lambda k-i$ would be expected for the N.PST:1PI). While the reason for the coda loss in this form is unclear, it this verbs confirms the conditioning of the *a $\rightarrow \varepsilon$ proposed here.
} 
Table 9: Distribution of stems in the CVCt transitive paradigm

\begin{tabular}{|c|c|c|c|c|c|c|}
\hline $\mathrm{A} \rightarrow \mathrm{P}$ & non-past & & past & & imperative & \\
\hline $1 \mathrm{~s} \rightarrow 3$ & strong- $u$ & sospt-u & strong-t $t \Lambda$ & sosp-ts & & \\
\hline $1 \mathrm{DI} \rightarrow 3$ & weak-i & $s \theta p-i$ & weak-iti & $s \theta p-i t i$ & & \\
\hline $1 \mathrm{DE} \rightarrow 3$ & weak- $u$ & $s \theta p-u$ & weak-utu & sep-utu & & \\
\hline $1 \mathrm{PI} \rightarrow 3$ & strong-ki & sosp-ki & strong-tiki & sosp-tiki & & \\
\hline $1 \mathrm{PE} \rightarrow 3$ & strong-k $k$ & sosp-kn & strong-t $t k \Lambda$ & sosp-tıkı & & \\
\hline $2 \mathrm{~s} \rightarrow 3$ & Pi-strong- $\sharp$ & Pi-sospt-z & $P i$-strong-te & Pi-sosp-te & strong-e & sospt-e \\
\hline $2 \mathrm{D} \rightarrow 3$ & $P i$-weak- $i$ & $2 i-s \theta p-i$ & $2 i$-weak-iti & Pi-sep-iti & weak-ije & sөp-ije \\
\hline $2 \mathrm{P} \rightarrow 3$ & $2 i$-strong-ni & 2i-sô̂m-ni & $2 i$-weak-tcnu & $2 i-s \theta p-t \varepsilon n u$ & weak-nuje & sөp-nuje \\
\hline $3 \mathrm{~s} \rightarrow 3$ & strong- $u$ & sospt-z & strong-te & $s o \jmath p-t \varepsilon$ & & \\
\hline $3 \mathrm{D} \rightarrow 3$ & strong-su & sosp-su & strong-tesu & sosp-tesu & & \\
\hline $3 \mathrm{P} \rightarrow 3$ & strong-nu & sosp-nu & strong-tenu & sosp-tenu & & \\
\hline $1 \mathrm{~S} \rightarrow 2$ & strong-ne & sôิm-nE & strong-teni & sô̂m-teni & & \\
\hline $2 / 3 \mathrm{~s} \rightarrow 1 \mathrm{~s}$ & $i$-strong- $\not \Lambda \Lambda$ &  & $i$-weak- $\iota t \wedge$ & $2 i-s \theta p-\Lambda t \Lambda$ & weak- $\wedge j e$ & sөp-ıje \\
\hline $3 \mathrm{~S} \rightarrow 1 \mathrm{PI}$ & $i$-strong-ki & ?i-sosp-ki & $i$-strong-tiki & 2i-sosp-tiki & strong-kıje & sosp-kıje \\
\hline
\end{tabular}

Table 10: Borrowings from Nepali exhibiting the fronting vowel shift

\begin{tabular}{lll}
\hline Nepali & Meaning & Khaling \\
\hline kam & work & $k \bar{\varepsilon} m$ \\
$\boldsymbol{k}^{h}$ orsani & chilli & $k^{h}$ ers $\hat{j} j$ \\
bud $^{h}$ & wife & buri \\
dud $^{h}$ & milk & dî̀t $t$ \\
\hline
\end{tabular}

displays a / $\Lambda$ alternation like roots with velar codas (jnl-u N.PST:1SG $\rightarrow 3 \mathrm{SG}$, $j \bar{a} l-k i$ N.PST:1PI $\rightarrow 3 \mathrm{SG}$ ). This exception is due to the fact that this verb was borrowed from Thulung (a neighbouring Kiranti language) after the vowel shift took place.

The fronting shift as defined here is confirmed by the fact that some borrowings from Nepali do present the sound shifts that have been postulated on the exclusive basis of internal reconstruction.

\subsection{Lowering}

The high vowels ${ }^{*}, * u$ in pre-Khaling are lowered to $\Lambda$, and $* o$ changes to os in closed syllables with a non-velar coda. Closed syllables occur in forms with consonant-initial suffixes, where resyllabification is not possible. ${ }^{8}$ For instance, in the pre-Khaling form *lom-ki (search-NPST:1PI $\rightarrow 3 \mathrm{~s}$ ), the coda * $m$ cannot be resyllabified, and since the verb stem remains a closed syllable, its vowel cannot undergo the fronting shift. This form fulfils the conditions for lowering to occur and $* o$ regularly changes to the diphthong $o \boldsymbol{s}$ in this context, yielding the attested form los̄m-ki.

\footnotetext{
${ }^{8}$ See section 3.4 for the case of CVCt verb roots.
} 
This sound change predicts that there should not be in Khaling any words with the vowels $i, u, o$ or their fronted equivalents $\boldsymbol{u}$ and $\boldsymbol{\theta}$ in closed syllables. Yet, such words are indeed attested, but come from different origins (reduction of polysyllables and borrowings).

\subsection{Backing}

The only vowel affected by the backing change is $i$. This vowel changes to $\Lambda$ in closed syllables with a velar coda followed by an obstruent. The preKhaling rhymes *-in and *ik change to $-\bar{u}$ : and $-\hat{u}:$ respectively when followed by a sonorant. When occurring at the end of a word, *-in undergoes vowel backing to $-\Lambda \eta$ while ${ }^{*}-i k$ changes to $-\hat{u}$ :

For instance, the pre-Khaling forms *sin-na 'ask, infinitive' and *sin-ki 'ask.N.PST.1PI $\rightarrow 3 \mathrm{SG}^{\prime}$ ' respectively become $s \bar{u}$-ne (before a sonorant) and $s \bar{n} \eta$ - $k i$ (before an obstruent).

In the southern Khaling dialects, ${ }^{*}-i n$ and ${ }^{*}-i k$ in the verbal paradigm verbs appear as $-\bar{\Lambda}:$ and $-\hat{\Lambda}:$ respectively before sonorants. This is however most probably an analogical development unifying the vocalism of all strong stem forms.

\subsection{The case of CVCt roots}

As all Kiranti languages, Khaling has transitive roots with complex codas, the second element of which is always $t$. Most of these roots are historically analysable as containing the $-t$ causative/applicative suffix (see Jacques 2013 for a description of its morphosyntactic functions).

These complex codas affect the application of the sound laws defined above: we find strong stems almost everywhere in the paradigm, even before most vowel-initial clusters, where the final $-t$ of the verb root is resyllabified with the suffix. For instance, $|k r i p t|$ 'cut' $+-t 3 \mathrm{SG} \rightarrow 3$ gives krıp.t- $t$ 'He cuts it' with a strong stem (with backing rule).

Weak stems are restricted to inverse forms, as well as first and second dual, and second plural in the past and imperative paradigms. The reason for this cluster simplification is unclear and does not warrant positing a historical sound law of cluster simplification to account for its distribution. The most likely explanation is that this allomorphy is analogical with corresponding simple coda paradigms, especially in the case of inverse forms.

\section{Tonogenesis in Khaling}

The contrast between level and falling tones has at least two distinct diachronic origins. First, some contrasts originate from the evolution of codas. Second, other tonal contrasts were created by the reduction of disyllables into monosyllables through loss of the final vowel. 
In this section, sound laws are demonstrated whenever possible on the basis of data from nouns rather than verbs, and using comparative data from other Kiranti languages. This way of establishing sound laws limits the risk of circular reasoning, which is particularly serious when doing internal reconstruction in a single-language basis.

\subsection{Tonal contrasts from codas}

The first origin of tonal contrast in Khaling is the evolution (preservation or change) of codas, as discovered by Michailovsky (1975). In pre-Khaling, the eight codas can be reconstructed on the basis of internal reconstruction: three stops ${ }^{*}-p,{ }^{*}-t$ and ${ }^{*}-k$, three nasals ${ }^{*}-m *-n$ and ${ }^{*}-\eta j$ and two nonnasal sonorant $*-r$ and $*-1$. Of these eight codas, four $(*-t, *-k, *-n$ and $*-\eta)$ undergo changes in some contexts.

Obstruent vs sonorant codas develop respectively falling tone and level tone in monosyllables and stress syllables within polysyllabic words.

\subsubsection{Obstruents and falling tones}

The final stops $*-k$ and $*-t$ induce falling tone and change respectively to compensatory lengthening and $-j$ in word-final position and before sonorants, as can be assessed by internal reconstruction (Jacques et al. 2012), confirmed with comparative data from Limbu and Dumi (see Table 11, Dumi and Limbu data respectively from van Driem 1993 and Michailovsky 2002). The coda $-k$ also induces backing and rounding in the case of the vowels $* a$ and $* i$ : pre-Khaling *-ak and *-ik become $-\hat{o}$ : and $-\hat{u}$ : respectively. It is interesting to note that this sound change should lead us to expect $a / \Lambda /-\hat{o}:$ in the Khaling system but only a / $\Lambda$ / $\hat{a}$ : is observed as was shown in the previous section. This suggests that the paradigms of verbs with roots in -ak have undergone analogy, and remade the falling tone forms. ${ }^{9}$

Table 11: Examples of falling tones originating from final stops

\begin{tabular}{lllll}
\hline Pre-Khaling & Limbu & Dumi & Khaling & Meaning \\
\hline "bit & pit & bhiri & bîj & cow \\
"met & met & me:?e & mêj & wife \\
"rak & yak & & rô: & cliff \\
"pak & phak & poro & pô: & pig \\
"?ik & ik & & ?ût: & field \\
\hline
\end{tabular}

Before stops, ${ }^{*}-k$ remains $-k$, while ${ }^{*}-t$ changes to $c ̧$ before labials and velars. ${ }^{10}$

\footnotetext{
${ }^{9}$ Probably on the basis of forms preserving the $-k$, such as first plural.

${ }^{10}$ The effect of this sound law is still visible in the paradigm of $|-t|$ coda verbs such as
} 
The coda *-p remains a stop in Khaling, but can be nasalized to $-m$ with falling tone if followed by a nasal-initial suffix as in the infinitive and various verbal forms. Pre-Khaling ${ }^{*} t$ followed by a nasal is likewise nasalized to $-n$ with falling tone.

Table 12: Examples of falling tones originating from the nasalization of obstruents (infinitive verb forms)

\begin{tabular}{|c|c|c|c|c|}
\hline Pre-Khaling & Limbu & Dumi & Khaling & Meaning \\
\hline "lop-na & & lop-ni & 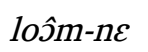 & to catch \\
\hline "rep-na & yeps- & repni & rêm-ne & to stand \\
\hline "set-na & set- & setni & sên-nE & to kill \\
\hline
\end{tabular}

\subsubsection{Sonorants and level tones}

The final sonorants $-m,-r,-l$ are preserved without change and develop level tone in word-final position, as shown in Table 13.

Table 13: Examples of level tones in syllables with sonorant codas

\begin{tabular}{|c|c|c|c|c|}
\hline Pre-Khaling & Limbu & Dumi & Khaling & Meaning \\
\hline "lam & lam & lam & $l \bar{\varepsilon} m$ & road \\
\hline${ }^{*} \mathrm{rDm}$ & yam & ram & rō̄m & body \\
\hline "lem & & le:m & lèm & tongue \\
\hline *ser & & se:r & $s \bar{e} r$ & louse \\
\hline${ }^{*} k^{h} u r$ & & $k^{h}$ ir & $k^{h} \bar{\Lambda} r$ & hand \\
\hline *kpr & & kar & $k o \bar{r} r$ & wound \\
\hline$*$ del & $t \varepsilon n$ & de:l & $d \bar{e} l$ & village \\
\hline *tulna & & tilni & $t \overline{l n} \ln$ & raise (cattle in an enclosed space) \\
\hline
\end{tabular}

The pre-Khaling coda * $-n$ changes to $-j$ word-finally and before almost all consonants; ${ }^{11}{ }^{*}-\eta$ is preserved word-finally, between vowels and before obstruents, but it manifests as compensatory lengthening of the previous


as final $*-k$ ). All closed syllables from syllables with the pre-Khaling coda $*-n$ and $*-\eta$ word-finally have level tone.

If the loss of obstruents were the only origin of falling tones, and the sonorant codas the only origin of level tone, we would expect a nearcomplementary distribution between the two tonal categories: only rhymes

\footnotetext{
$\left|k^{h} o t\right|$ 'go'. For instance, the first person plural forms (with the velar-initial suffixes $-k i$ and

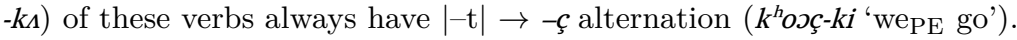

${ }^{11}$ It is possible that it is preserved before dental stops, but the evidence requires some analysis; this question is discussed in section 5 .
} 
Table 14: Examples of level tones in syllables with ${ }^{*}-n$ and ${ }^{*}-\eta$ Pre-Khaling codas

\begin{tabular}{|c|c|c|c|c|}
\hline Pre-Khaling & Limbu & Dumi & Khaling & Meaning \\
\hline *lup & lup & $1 u$ & $\operatorname{lu} \eta$ & stone \\
\hline$* \sin$ & $\sin$ & $s i$ & $s \bar{\Lambda} \eta$ & tree \\
\hline *sin-na & & sinni & sū:ne & ask \\
\hline "tson-na & & tsonni & tsō̄jne & hop forward \\
\hline
\end{tabular}

with the Khaling codas $-j$ and $-m$ (and the latter, only word-internally before a nasal) should have a tonal contrast; all other syllables ending in a sonorant should be level tone, and all word-final open syllable long vowels should be falling tone, and only include -ố, - $\hat{e}:$ and $-\hat{u}:$.

Yet, there appear to be no gaps in the distribution of tones in Khaling: the contrast is present in all long vowel open syllables and in all syllables with sonorant codas. Thus, at least one other origin should be postulated to account for the types of falling and level tone syllables not predicted by the sound laws proposed in this section.

\subsection{Falling tones originating from the reduction of disyllables}

The reduction of disyllables into monosyllables is another common origin for falling tones. In inherited disyllabic nouns, the vowel and coda of the second syllable are lost in certain conditions (see below), and either the coda of the first syllable or the onset of the second syllable becomes the coda.

Evidence for this syllable reduction mainly comes from comparison with Dumi, where the lost vowel is still present. The very name of the Khaling people, $k^{k} \hat{\mathcal{E}} l$, illustrates this sound change: the pronunciation "khalin was borrowed into Nepali before syllable reduction took place, a fact which suggests that it occurred very recently. This sound change is best illustrated by the minimal pair $p^{h} \hat{\mathcal{E}} r$ 'trap, snare' vs $p^{h} \overline{\mathcal{E}} r$ 'near', which corresponds to phari 'trap' vs phar 'near' in Dumi (data from Rai 2011).

All good examples (see Table 15) involve words with a high vowel in the second syllable. Mid-high and high vowels in the second syllable are immune to this sound change. These examples develop falling tone when the consonant preceding the lost vowel is a sonorant. ${ }^{12}$

In some cases, the second syllable could be of the type ${ }^{*}-\mathrm{Ci}$ (as in the time ordinal nêm 'in two days') or ${ }_{-}^{*} \mathrm{iC}$ (as in $k^{h} \hat{\mathcal{E}} l$ Khaling') but in most cases only an open syllable needs to be reconstructed.

The reduction of disyllables does not always result in a syllable with

\footnotetext{
${ }^{12} \mathrm{~A}$ third origin for falling tones results from vowel fusion after the loss of intervocalic ${ }^{*} w$. It is found in words like $g^{h} r \hat{\varepsilon}^{*}$ ' crab' $\leftarrow{ }^{*}$ ggrawa and $t \hat{\text { êt }} \leftarrow{ }^{*}$ tsowo, compare Dumi (Rai 2011) grawa 'crab' and tsuwo 'heart'.
} 
a final sonorant. When the internal cluster in pre-Khaling only contained obstruents, we obtain closed syllables with obstruent codas without tonal contrasts.

Thus, in mos 'bear' from "moksu, the vowel remains $o$ (does not change to os) due to the backing effect of the velar coda; the stop is then lost, leaving only an indirect trace, and only the second element $-s$ of the cluster remains after loss of the second vowel. Words ending in obstruent codas $-t,-k,-s$ in Khaling all originate from such reduced disyllables (or from loanwords), never from pre-Khaling monosyllables. The geminate stop codas have also been generated by this rule: they originate from aspirated stops or geminated stops that became word-final after the Syllable Reduction Rule.

Reconstructing the pre-Khaling form is impossible on Khaling-internal evidence: comparison with Dumi (and possibly other closely related languages) is necessary to recover the lost vowels and consonants.

Table 15: Examples of falling tone or obstruent final monosyllables originating from the simplification of disyllabic nouns

\begin{tabular}{|c|c|c|c|}
\hline Pre-Khaling & Dumi & Khaling & Meaning \\
\hline$* t s i l i$ & tsili & tsîl & anger \\
\hline *nini & nini & nîn & aunt (FZ) \\
\hline "meri & miri & mêr & tail \\
\hline "rali & ra:li & $r \hat{\varepsilon} l$ & centipede \\
\hline "sali & sali 'nail, talon' & $s \hat{\varepsilon} l$ & foot \\
\hline "noru & nuri & $n \hat{\theta} r$ & tiger \\
\hline *nolu & nuli & $n \hat{\theta} l$ & daytime \\
\hline $\begin{array}{l}{ }^{*} k^{h} a l i n \\
* n a m-n i\end{array}$ & na:mni & $\begin{array}{l}k^{h} \hat{\varepsilon} l \\
n \hat{\varepsilon} m\end{array}$ & $\begin{array}{l}\text { Khaling } \\
\text { in two days }\end{array}$ \\
\hline "pipi & pipi & pip & grandmother \\
\hline "moksu & moksi & mos & bear \\
\hline${ }^{*} p^{\prime} k^{h} u$ & $p \dot{i} k^{h \dot{H}}$ & pek & dirt \\
\hline
\end{tabular}

Exceptions to the Syllable Reduction Rules in nouns are extremely rare, and may reflect borrowings, or special contexts where the rule does not apply; this question is left for future investigations.

Table 16: Exceptions to the Syllable Reduction Rule

\begin{tabular}{lllll}
\hline Pre-Khaling & Limbu & Dumi & Khaling & Meaning \\
\hline "sendi & sendi & syendi & sēndu, sēndi & nail \\
??? & & mupu & mupu & belly \\
\hline
\end{tabular}

The application of the Syllable Reduction Rule appears to operate dif- 
ferently in verbs. Several verbal suffixes had high vowels in pre-Khaling: the first singular direct $-u^{13}$, the inclusive and exclusive dual $-i$ and $-u$ and the third/second transitive $-\boldsymbol{u} .{ }^{14}$

Table 17: Exceptions to the Syllable Reduction Rule

\begin{tabular}{|c|c|c|c|c|c|}
\hline Proto-Kiranti & Limbu & Dumi (past) & Pre-Khaling & Khaling & Meaning \\
\hline "lop-si & & $\operatorname{lup}^{h_{i}}$ & "lopí & lepi & we $_{\text {DI }}$ catch for him \\
\hline *set-si & $a-s \varepsilon t-s u$ & sitsi & "setsí & setsi & we $_{\text {DI }}$ kill him \\
\hline *kok-si & & $k u k^{h i}$ & *kokí & $k e k i$ & we $_{\text {DI }}$ are able to do it \\
\hline$*$ lom-si & & lumi & *lomí & lemi & we $_{\text {DI }}$ look for him \\
\hline *lop-u & & $\operatorname{lup}^{h \dot{i}}$ & *lóbu & lēe:bu & he catches him \\
\hline "set-u & ser-u & sidi & *sédu & $s \bar{e}: d t$ & he kills him \\
\hline *kok-u & & $k u k h i$ & "kógu & $k \bar{\theta}: g \psi$ & he is able to do it \\
\hline *lom-u & & lumi & "lómu & lē:mu & he looks for him \\
\hline
\end{tabular}

The dual inclusive with a suffix $-i$ in Dumi and Khaling instead of $-s i$ or $-s u$ (from * $s i+u$ ) in other Kiranti languages suggests that a cluster reduction rule took place as early as the common ancestor of Khaling and Dumi, as summarized in Table $17:^{15}$ word-internal Proto-Kiranti * stop+s clusters became intervocalic unvoiced stops in pre-Khaling (and Khaling), while intervocalic unvoiced stops in proto-Kiranti were voiced in Pre-Khaling (but after the split from Dumi and Khaling).

Other word-internal clusters (such as ${ }^{*}$ sonorant $+\mathrm{s}$ ) were simplified by dropping the $* s$ without a trace. This rule entails that all word-internal clusters Cs in pre-Khaling (and even more in Khaling) are secondary, and cannot be inherited from proto-Kiranti. It also explains why the dual forms of verbs with $-C t$ roots lost the -t- in dual forms and why the weak stems are found there: it results from an early reduction of the proto-Kiranti *-Ctscluster into simple ${ }^{*} \mathrm{C}$ in pre-Khaling.

For instance the first dual inclusive of the root $\mid$ kript 'cut' is kripi in Khaling. The following stages can be proposed: Proto-Kiranti *kript-si $\rightarrow$ "krippi $\rightarrow$ pre-Khaling "kripí $\rightarrow$ Khaling kripi.

In verbal paradigms, the Syllable Reduction Rule only applied to the second syllable of trisyllabic forms, when this second syllable contained a high vowel and was not stressed.

\footnotetext{
${ }^{13}$ This ending corresponds to -up in other Kiranti languages; pre-Khaling *-up normally remains $-u \eta$ word finally in Japhug (and $-\bar{u}$ : before sonorants). This irregularity is left for further research.

${ }^{14}$ This suffix regularly reflects pre-Khaling *-u.

${ }^{15}$ This rule is unrelated to the Syllable Reduction Rule seen above, whose application is entirely different as in mos $\leftarrow$ "moksú 'bear'. The Syllable Reduction Rule only applied to secondary clusters in compound nouns, not to the more ancient verbal morphology. Khaling still has $-C s$ - clusters, but these result from the Syllable Reduction Rule, as we explain below.
} 
It applies for instance with the $3 \rightarrow 3 \mathrm{DU}$ and $3 \rightarrow 3 \mathrm{PL}$ of the transitive paradigm, as illustrated by the data in Table $18 .{ }^{16}$

Table 18: The application of the Syllable Reduction Rule in the verbal system

\begin{tabular}{lll}
\hline Pre-Khaling & Khaling & Meaning \\
\hline "lóbu-nV & lê:p-nu & they catch him \\
"sédu-nV & sêtt-nu & they kill him \\
"lómu-nV & lêm-nu & they look for him \\
\hline
\end{tabular}

On the other hand, it does not apply to first singular and dual forms, where the ending was stressed, as shown in Table 19 (except for $-t$ and $-\boldsymbol{n}$ roots, such as the verb $\mid$ set $\mid$ 'kill', past dual inclusive ses-ti).

Table 19: The Syllable Reduction Rule in forms with stress-bearing endings in pre-Khaling

\begin{tabular}{lll}
\hline Pre-Khaling & Khaling & Meaning \\
\hline "lop-íti & lep-iti & we \\
"lom-íti & lem-iti & we $_{\text {DI looked him }}$ lor him \\
\hline "sets-íti & ses-ti & we $_{\text {DI }}$ killed him \\
\hline
\end{tabular}

\section{Tonogenesis and verbal morphology}

Most of the tonal alternations observed in the Khaling verbal system (see Jacques et al. 2012) can be accounted for by the two sound changes described above, namely the development of falling vs level tone from obstruents vs sonorants and the Syllable Reduction Rule.

The falling tones originating from obstruents (in verbs with roots in stop codas) occur in two situations (see Table 20).

First, they are found in forms that had nasal-initial suffixes in preKhaling, i.e. the infinitive and second plural non-past of all verbs, the first singular third plural non-past of intransitive verbs and the $1 \mathrm{SG} \rightarrow 2 \mathrm{SG}$ and $3 \rightarrow 1 \mathrm{sg}$ forms of transitive verbs. In these forms, the final obstruents $-p(t)$ and $-t(t)$ are nasalized to $-m$ and $-n$ respectively with falling tone. Final $-k(t)$ is dropped with compensatory lengthening and falling tone. The first singular suffix $-\eta \Lambda \Lambda$ works differently from other nasal suffixes: it nasalizes $-p(t)$ and $-k(t)$ to $-m$ and $-\eta$ with falling tone (for $-k(t)$ it can also optionally

\footnotetext{
${ }^{16}$ The reconstruction of the dual and plural $-s u$ and $-n u$ in pre-Khaling is uncertain; the expected vowel in these suffixes should have been either $i$ or $u$.
} 
change to compensatory lengthening), while $-t(t)$ changes to $-j$ with falling tone before it.

Second, falling tone forms occur in all stems that appear word-finally (first and second person singular or intransitive verbs and $3 \rightarrow 2 \mathrm{SG}$ of transitive verbs) for verbs with roots in $-t(t)$ and $-k(t)$. The coda of verbs in $-p(t)$ does not disappear word-finally.

Table 20: Falling tones from lost stops in the Khaling verbal system

\begin{tabular}{|c|c|c|c|c|c|}
\hline Verb & Meaning & Infinitive & Non-Past 1sG & $3 \mathrm{SG}$ & $1 \mathrm{PI}$ \\
\hline$P \mathcal{E}$ & say & 2र्En & $2 \hat{\varepsilon} j$ & $2 \hat{\varepsilon} j$ & \\
\hline$\left|k^{h} o t\right|$ & go & $k^{h} O \hat{\jmath} n-n \mathcal{E}$ & $k^{h} O \hat{\jmath j}-\eta \eta \Lambda$ & $k^{h} O \hat{\jmath} j$ & $k^{h} O \partial c ̧-k i$ \\
\hline$\left|p^{h} u k\right|$ & get up & $p^{h} \hat{u} \hat{u}-n \mathcal{E}$ & $p^{h} \hat{u} \eta-\not \Lambda \Lambda / p^{h} \hat{u}:-\not \jmath \Lambda$ & $p^{h} \hat{u}:$ & $p^{h} u k-k i$ \\
\hline$|r e p|$ & stand & rêm-nE & rêm-ı̆ & rê:p & $r e p-k i$ \\
\hline
\end{tabular}

Verbs with sonorant final roots present level tone in the corresponding forms, as illustrated by Table 21 .

Table 21: Level tones in sonorant stems in the Khaling verbal system

\begin{tabular}{|c|c|c|c|c|c|}
\hline Verb root & Meaning & Infinitive & Non-Past 1sG & $3 \mathrm{SG}$ & 1PI \\
\hline $\mid t s^{h}$ om $\mid$ & dance & $t s^{h} o \bar{J} m-n \varepsilon$ & $t s^{h} O \bar{\jmath} m-\eta \Lambda$ & $t s^{h} O \bar{J} m$ & $t s^{h} O \bar{J} m-k i$ \\
\hline $\mid$ tson $\mid$ & jump & tsō̄j-nE & $t s o \bar{\jmath} j-\eta \jmath \Lambda$ & tsō̄j & tsō̄j-ki \\
\hline$\left|k^{h} O \eta\right|$ & come (from below) & $k^{h} \bar{O}:-n \mathcal{E}$ & $k^{h} \bar{O}:-\not M \Lambda$ & $k^{h} \bar{O} \eta$ & $k^{h} \bar{o} \eta-k i$ \\
\hline
\end{tabular}

Most of the tonal alternations not explained by the loss of obstruents can be accounted for by the Syllable Reduction Rule. In the verbal system, this does not apply to disyllabic forms, but does occur in tri-syllabic forms (section 4.2): the second syllable of a trisyllabic verb form in pre-Khaling drops if it had a high vowel ${ }^{*} i$ or $* u$.

Table 22 illustrates the application of the Syllable Reduction rule in $3 \rightarrow 3 \mathrm{PL}$ forms (in comparison with $3 \mathrm{SG} \rightarrow 3 \mathrm{SG}$ forms, where it does not occur).

Table 22: Falling tones from lost syllables in the Khaling verbal system

\begin{tabular}{|c|c|c|c|}
\hline Verb root & Meaning & Non-Past 3SG & Non-Past 3PL \\
\hline $\mid$ set $\mid$ & kill & $s \bar{e}: d-u \leftarrow{ }^{*}$ sédu & sêtt-nu $\leftarrow$ *sédu-nV \\
\hline $\mid p^{h}$ rok $\mid$ & untie & $p^{h} r \bar{\theta}: g-u \leftarrow{ }^{*} p^{h} r o ́ g u$ & $p^{h} r \hat{\theta}: k-n u \leftarrow{ }^{*} p^{h}$ rógu-nV \\
\hline $\mid$ lom $\mid$ & look for & lë:m-u $\leftarrow$ "lómu & lêm-nu $\leftarrow$ "lómu-n $V$ \\
\hline $\begin{array}{l}\mid b^{h} \text { ert } \mid \\
\mid \text { sent } \mid\end{array}$ & $\begin{array}{l}\text { cause to fly } \\
\text { see }\end{array}$ & $\begin{array}{l}b^{h} \bar{e} r d-u \leftarrow \text { "bhérdu } \\
\text { sēnd-u } \leftarrow \text { "séndu }\end{array}$ & $\begin{array}{l}\text { bhêr-nu } \leftarrow \text { "bhérdu-nV } \\
\text { sên-nu } \leftarrow \text { "séndu-nV }\end{array}$ \\
\hline
\end{tabular}

The third person plural of intransitive paradigm is $-n u$, and appears to be superficially similar to that of the transitive paradigm. Yet, no falling 
tone occurs in this form for verbs with roots in sonorant coda. For instance $\left|b^{h} e r\right|$ 'fly', the intransitive counterpart of $\left|b^{h} e r t\right|$ 'cause to fly' has a third person plural non-past $b^{h} \bar{e} r-n u$. This difference is due to the fact that the endings of the transitive and intransitive paradigms were different in preKhaling: the former had a compound suffix ${ }^{*}-u-n V^{17}$ while the latter had simple $* n V$. In the third plural of the intransitive paradigm, there was no high vowel between the verb stem and the plural suffix, and hence the Syllable Reduction Rule could not apply to generate a falling tone.

The Syllable Reduction Rule also applies in past tense forms (third and second person direct), as illustrated by Table 23 .

Table 23: Falling tones from lost syllables in the Khaling verbal system, Past forms

\begin{tabular}{|c|c|c|}
\hline Verb root & Meaning & Past 3SG \\
\hline $\begin{array}{l}\mid \text { set } \mid \\
\mid p^{h} \text { rok } \mid \\
\mid \text { lom } \mid\end{array}$ & $\begin{array}{l}\text { kill } \\
\text { untie } \\
\text { look for }\end{array}$ &  \\
\hline $\begin{array}{l}\mid b^{h} \text { ert } \mid \\
\mid \text { sent } \mid\end{array}$ & $\begin{array}{l}\text { cause to fly } \\
\text { see }\end{array}$ & $\begin{array}{l}b^{h} \hat{e} r-t \varepsilon \leftarrow \text { *bhérduta } \\
\text { sên-tc } \leftarrow \text { "sénduta }\end{array}$ \\
\hline
\end{tabular}

In the paradigm of verbs with roots in $-t$ coda, the final obstruent drops before the past tense suffix $-t \varepsilon$, resulting in an open syllable long vowel with falling tone, avoiding a long vowel before geminated $t$. For instance, the following intermediary steps can be posited for the third person past form

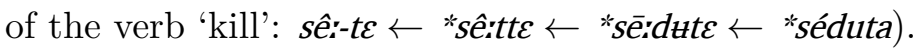

All tonal alternations in the direct transitive paradigm and the inverse non-past paradigm can be accounted for using the rules explained above: SF (stop coda to falling tone), N (nasalization of stop coda), SR (Syllable Reduction Rule), L (lengthening of accented vowel in open syllable). The forms where each of these rules is applied in the transitive paradigm of verb with stop final roots and sonorant final roots are presented in Tables 24 and 25 respectively.

Thus, nearly all tonal alternations in the Khaling verbal system are the result of a mechanical application of sound changes whose existence can be independently proven by applying the comparative method to Kiranti languages.

\section{Unexplainable alternations}

There remain a residue of forms with falling tones that cannot be accounted for by either scenario, in the past tense of the intransitive paradigm, the

\footnotetext{
${ }^{17}$ The reconstruction of the vowel in pre-Khaling for the plural suffix $-n u$ is still unclear.
} 
Table 24: Tonal alternations in the transitive paradigm of the verb | set |'kill'

\begin{tabular}{|c|c|c|c|c|c|c|}
\hline $\mathrm{A} \rightarrow \mathrm{P}$ & Non-past & Origin & Past & Origin & Imperative & Origin \\
\hline $1 \mathrm{~s} \rightarrow 3$ & sed-u & & $s e \hat{i}-t \Lambda$ & $\mathrm{L}+\mathrm{SR}$ & & \\
\hline $1 \mathrm{DI} \rightarrow 3$ & sets $-i$ & & $s e s-t i$ & & & \\
\hline $1 \mathrm{PI} \rightarrow 3$ & $s e c ̧-k i$ & & seç-tiki & & & \\
\hline $2 \mathrm{~S} \rightarrow 3$ & Pi-sē:d-u & $\mathrm{L}$ & 2i-sề-tz & $\mathrm{L}+\mathrm{SR}$ & sē:d-e & $\mathrm{L}$ \\
\hline $2 \mathrm{D} \rightarrow 3$ & 2i-sets-i & & 2i-ses-ti & & sets-ije & \\
\hline $2 \mathrm{P} \rightarrow 3$ & 2i-sên-ni & $\mathrm{N}$ & 2i-ses-tcnu & & ses-nuje & \\
\hline $3 \mathrm{~s} \rightarrow 3$ & $s \bar{e}: d-u$ & $\mathrm{~L}$ & $s \hat{e}_{i}^{\prime}-t \mathcal{E}$ & $\mathrm{L}+\mathrm{SR}$ & & \\
\hline $3 \mathrm{D} \rightarrow 3$ & sêts-su & $\mathrm{L}+\mathrm{SR}$ & sề-tcsu & $\mathrm{L}+\mathrm{SR}$ & & \\
\hline $3 \mathrm{P} \rightarrow 3$ & sê:t-nu & $\mathrm{L}+\mathrm{SR}$ & sê:-tcnu & $\mathrm{L}+\mathrm{SR}$ & & \\
\hline $1 \mathrm{~s} \rightarrow 2$ & sên-nE & $\mathrm{N}$ & sên-tcni & $\mathrm{N}$ & & \\
\hline $2 / 3 \mathrm{~s} \rightarrow 1 \mathrm{~s}$ &  & $\mathrm{SF}$ & 2i-ses-tn & & sets-ıje & \\
\hline $3 \mathrm{~s} \rightarrow 1 \mathrm{PI}$ & Pi-seç-ki & & Pi-seç-tiki & & seç-kıje & \\
\hline
\end{tabular}

inverse transitive paradigm and the direct past tense $2 \mathrm{PL} \rightarrow 3$. We illustrate the problem with data from the intransitive paradigm exclusively.

As presented in Table 26, singular and plural second and third person past and imperative forms have a falling tone in paradigms of verbs with roots in sonorant codas.

These forms appear to be superficially identical the corresponding ones of the transitive paradigm. For instance, the third singular of the past tense $t s^{h} \hat{\theta} m-t \varepsilon$ 'he danced' has the same alternation as that of the transitive

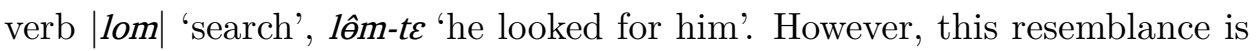
misleading. If we observe the intransitive paradigm of verb whose root has a stop coda, as in Table 27, we see that the verb stem has a short vowel in the corresponding forms.

The difference between the transitive and intransitive paradigms of verbs with roots in stop coda can be illustrated by the third person past tense of

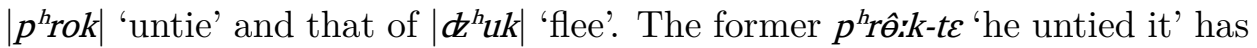
a long vowel and non-contrastive falling tone, while the latter has a short

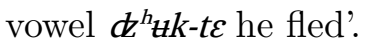

Hence, it is not possible to reconstruct, for the intransitive past tense, a trisyllabic form with word-initial stress (like $\left.p^{h} r \hat{\theta}: k-t \varepsilon \leftarrow{ }^{*} p^{h} r o ́ g u t a\right)$. It could be possible to account for the intransitive paradigms in Table 26 and 27 by positing a stress-final pattern in the past tense of intransitive verbs in pre-

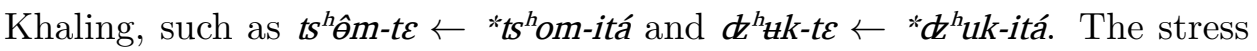
not being placed on the verb stem, vowel lengthening does not occur, and not being placed on the second syllable, the Syllable Reduction Rule can apply and generate the falling tone in verbs with roots in sonorant codas.

However, there is no compelling comparative evidence from any Kiranti 
Table 25: Tonal alternations in the transitive paradigm of the verb $\mid$ lom $\mid$ 'search'

\begin{tabular}{|c|c|c|c|c|c|c|}
\hline $\mathrm{A} \rightarrow \mathrm{P}$ & Non-past & Origin & Past & Origin & Imperative & Origin \\
\hline $1 \mathrm{~s} \rightarrow 3$ & lom-u & & lomu-ts & & & \\
\hline $1 \mathrm{DI} \rightarrow 3$ & lem-i & & lem-iti & & & \\
\hline $1 \mathrm{PI} \rightarrow 3$ & $l o \bar{m}-k i$ & & lō̄m-tiki & & & \\
\hline $2 \mathrm{~s} \rightarrow 3$ & Pi-lē:m-\# & $\mathrm{L}$ & 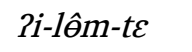 & $\mathrm{L}+\mathrm{SR}$ & lē:m-e & $\mathrm{L}$ \\
\hline $2 \mathrm{D} \rightarrow 3$ & 2i-lem-i & & Pi-lem-ti & & lem-ije & \\
\hline $2 \mathrm{P} \rightarrow 3$ & 2i-lō̄m-ni & & Ri-lôm-tcnu & & lêm-nuje & \\
\hline $3 \mathrm{~s} \rightarrow 3$ & $l \bar{\theta}: m-u$ & $\mathrm{~L}$ & lôm-tE & $\mathrm{L}+\mathrm{SR}$ & & \\
\hline $3 \mathrm{D} \rightarrow 3$ & lôm-su & $\mathrm{L}+\mathrm{SR}$ & lêm-tesu & $\mathrm{L}+\mathrm{SR}$ & & \\
\hline $3 \mathrm{P} \rightarrow 3$ & lêm-nu & $\mathrm{L}+\mathrm{SR}$ & lôm-tcnu & $\mathrm{L}+\mathrm{SR}$ & & \\
\hline $1 \mathrm{~s} \rightarrow 2$ & lō̄m-nE & & lō̄m-teni & & & \\
\hline $2 / 3 \mathrm{~s} \rightarrow 1 \mathrm{~s}$ & 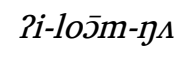 & $\mathrm{SF}$ & 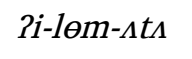 & & lem-ıje & \\
\hline $3 \mathrm{~S} \rightarrow 1 \mathrm{PI}$ & Pi-lō̄m-ki & & 2i-lō̄m-tiki & & lō̄m-kıje & \\
\hline
\end{tabular}

language for a high vowel in any of these forms between the verb stem and the suffix. One possible reason for this is that some languages underwent vowel reduction in trisyllables like Khaling. In Dumi, as can be seen in Table 28 , all vowels located between the verb stem and the Non-Past ${ }^{18}-t$ suffix have been lost, even in forms where Khaling has preserved them. ${ }^{19}$

Until clear evidence is found in another Kiranti language for reconstructing *-ita rather than -*ta in the second and third singular and plural past forms, the hypothesis laid out in this section must be regarded as tentative. ${ }^{20}$

\section{Conclusion}

In this paper, we have shown that most tonal alternations in Khaling can be accounted for by two main groups of sound changes: the development of tonal contrast following the loss of codas and the Syllable Reduction Rule.

Some tonal alternations in the intransitive paradigm cannot be explained yet, and future investigation on this topic will have to take into account

\footnotetext{
${ }^{18}$ In Dumi, the Past and Non-Past paradigms are reversed in comparison with other Kiranti languages. Thus, the Khaling Past paradigm corresponds to the Dumi Non-Past.

${ }^{19}$ The syllable Reduction Rule that took place in Dumi is of course very different, and independent from, that found in Khaling, since it does not apply to disyllabic nouns.

${ }^{20}$ The Past tense suffix probably originates from an independent verb (perhaps the verb 'put', in Khaling $|t a|)$. Evidence for this comes from Bantawa (Doornenbal 2009: 16572 ), where the cognate past tense suffix $-d a-$ can still occur as an independent word and receive the second person prefix $t \dot{t}-$. Thus, this question cannot be satisfactorily answered without an account of the history of doubly conjugated verbs in Khaling and other Kiranti languages. This topic is not discussed in this paper, due to lack of data on most relevant languages.
} 
Table 26: Distribution of the stems in the intransitive paradigm of the verb $\mid t^{h}$ om $\mid$ 'dance', sonorant final

\begin{tabular}{|c|c|c|c|c|c|c|}
\hline S & Non-past & Origin & Past & Origin & Imperative & Origin \\
\hline $1 \mathrm{~s}$ & $t s^{h} O \bar{J} m-\eta \Lambda$ & & $t s^{h} \theta m-\Lambda t \Lambda$ & & & \\
\hline 1DI & $t s^{h} \theta m-i$ & & $t s^{h} \theta m-i t i$ & & & \\
\hline 1PI & $t s^{h} o \bar{J} m-k i$ & & $t s^{h} O \bar{J} m-t i k i$ & & & \\
\hline $2 \mathrm{~s}$ & 2i-ts ${ }^{h} O \bar{\jmath} m$ & & 2i-ts ${ }^{h} \hat{\theta} m-t \mathcal{E}$ & $?$ & $t s^{h} \hat{\theta} m-j e$ & $?$ \\
\hline $2 \mathrm{D}$ & $P i-t s^{h} \theta m-i$ & & Pi-ts ${ }^{h} \theta m-i t i$ & & $t s^{h} \theta m-i j e$ & \\
\hline $2 \mathrm{P}$ & 2i-ts ${ }^{h} O \bar{J} m-n i$ & & Pi-ts ${ }^{h} \hat{\theta} m-t \varepsilon n u$ & $?$ & $t s^{h} \hat{\theta} m-n u j e$ & $?$ \\
\hline $3 \mathrm{~s}$ & $t s^{h} O \bar{s} m$ & & $t s^{h} \hat{\theta} m-t \varepsilon$ & $?$ & & \\
\hline $3 \mathrm{D}$ & $t s^{h} \theta m-i$ & & $t s^{h} \theta m-i t i$ & & & \\
\hline $3 \mathrm{P}$ & $t s^{h} O \bar{s} m-n u$ & & $t^{h}{ }^{h} \hat{\theta} m-t \varepsilon n u$ & $?$ & & \\
\hline
\end{tabular}

Table 27: Distribution of the stems in the intransitive paradigm of the verb $\left|\boldsymbol{k}^{h} u k\right|$ 'flee', stop final

\begin{tabular}{|c|c|c|c|c|c|c|}
\hline$S$ & Non-past & Origin & Past & Origin & Imperative & Origin \\
\hline $1 \mathrm{~s}$ & $\boldsymbol{c}^{h} \hat{u} \eta-\eta \Lambda$ & $\mathrm{L}+\mathrm{N}$ & $\boldsymbol{d}^{h} z k-\Lambda t \Lambda$ & & & \\
\hline $1 \mathrm{DI}$ & $d^{h} u k-i$ & & $\boldsymbol{c}^{h} \boldsymbol{u k - i t i}$ & & & \\
\hline 1PI & $\boldsymbol{d}^{h} u k-k i$ & & $\boldsymbol{d}^{h} u k-t i k i$ & & & \\
\hline $2 \mathrm{~s}$ & $P i-\mathbb{C}^{h} \hat{u}:$ & $\mathrm{SF}$ & $P i-d^{h} u k-t \varepsilon$ & & $\boldsymbol{c}^{h} t k-j e$ & \\
\hline $2 \mathrm{D}$ & $P i-\boldsymbol{c}^{h} \boldsymbol{u}-i$ & & Pi- $\boldsymbol{d}^{h} u k-i t i$ & & $\boldsymbol{d}^{h} \boldsymbol{u k - i j e}$ & \\
\hline $2 \mathrm{P}$ & $P i-\boldsymbol{d}^{h} \hat{u} \mathbf{u}-n i$ & $\mathrm{SF}$ & $P i-\boldsymbol{c}^{h} u k-t \varepsilon n u$ & & $\boldsymbol{d}^{h} u k$-nuje & \\
\hline $3 \mathrm{~s}$ & $\boldsymbol{d}^{h} \hat{u}:$ & $\mathrm{SF}$ & $\boldsymbol{d}^{h} u k-t \varepsilon$ & & & \\
\hline $3 \mathrm{D}$ & $\boldsymbol{d}^{h} u k-i$ & & $\boldsymbol{c}^{h} u k-i t i$ & & & \\
\hline $3 \mathrm{P}$ & $\boldsymbol{c}^{h} \hat{\mathrm{u}} \mathrm{i}-\mathrm{nu}$ & $\mathrm{SF}$ & $\boldsymbol{d}^{h} u k$-tenu & & & \\
\hline
\end{tabular}

reflexive paradigms and doubly conjugated verbs. Yet, additional data from the languages that are the most closely related to Khaling, in particular Dumi and Koyi, will be necessary to undertake this research.

\section{Notes}

I would like to thank Aimée Lahaussois, Jean-Léo Léonard, Boyd Michailovsky and Enrique Palancar for useful comments on previous version of this work, and Dhana Khaling Rai and his family for teaching me Khaling. I am responsible for any remaining error. Abbreviations follow the Leipzig glossing rules, except for the following: C consonant V vowel, DI / PI dual / plural inclusive DE / PE dual / plural exclusive. This research was funded by the HimalCo project (ANR-12-CORP-0006) and is related to the research strand LR-4.11 "Automatic Paradigm Generation and Language Description" of the Labex EFL (funded by the ANR/CGI).

Abbreviations follow the Leipzig glossing rules, except for the following: $\mathrm{C}$ 
Table 28: Comparison between Khaling and Dumi (intransitive $\mid t s^{h}$ om $\mid$ 'dance' vs transitive |lom| 'look for')

\begin{tabular}{|c|c|c|}
\hline $\mathrm{S}$ & Khaling Past & Dumi Non-past \\
\hline $1 \mathrm{~s}$ & $t s^{h} \theta m-\Lambda t \Lambda$ & tsum-to \\
\hline 1DI & $t s^{h} \theta m-i t i$ & tsum-ti \\
\hline 1PI & $t^{h}{ }^{h}$ ōm-tiki & tsəm-kiti \\
\hline $2 \mathrm{~s}$ & $2 i-t s^{h} \hat{\theta} m-t \varepsilon$ & a-tsum-ta \\
\hline $2 \mathrm{D}$ & $2 i-t s^{h} \theta m-i t i$ & $a-t s u m-t i$ \\
\hline $2 \mathrm{P}$ & $2 i-t s^{h} \hat{\theta} m-t \varepsilon n u$ & a-tsum-tini \\
\hline $3 \mathrm{~s}$ & $t s^{h} \hat{\theta} m-t \varepsilon$ & tsum-ta \\
\hline $3 \mathrm{D}$ & $t s^{h} \theta m-i t i$ & tsum-ti \\
\hline $3 \mathrm{P}$ & $t s^{h} \hat{\theta} m-t \varepsilon n u$ & ham-tsum-ta \\
\hline $1 \mathrm{~s}$ & lom-uts & lum-to \\
\hline 1DI & lem-iti & lum-ti \\
\hline $1 \mathrm{PI}$ & lō̄m-tiki & lom-kiti \\
\hline $2 \mathrm{~s}$ & Ri-lôm-tE & a-lum-ta \\
\hline $2 \mathrm{D}$ & 2i-lem-iti & $a-l u m-t i$ \\
\hline $2 \mathrm{P}$ & 2i-lôm-tenu & a-lum-tini \\
\hline $3 \mathrm{~s}$ & lôm-tE & lum-ta \\
\hline $3 \mathrm{D}$ & lem-iti & lum-ti \\
\hline $3 \mathrm{P}$ & lôm-tcnu & ham-lum-ta \\
\hline
\end{tabular}

consonant V vowel, DI / PI dual / plural inclusive DE / PE dual / plural exclusive.

\section{References}

Bickel, Balthasar, Goma Banjade, Martin Gaenszle, Elena Lieven, Netra Paudyal, Ichchha Purna Rai, Manoj Rai, Novel Kishore Rai \& Sabine Stoll. 2007. Free prefix ordering in Chintang. Language 83.1. 1-31.

Doornenbal, Marius. 2009. A Grammar of Bantawa: Grammar, paradigm tables, glossary and texts of a Rai language of Eastern Nepal.: Leiden University dissertation.

van Driem, George. 1990. The Fall and Rise of the Phoneme r in Himalayan Languages. Bulletin of the School of Oriental and African Studies 53.1. 83-86.

van Driem, George. 1993. A Grammar of Dumi. Berlin: Mouton de Gruyter.

Jacques, Guillaume. 2012. Agreement morphology: the case of Rgyalrongic and Kiranti. Language and Linguistics 13(1). 83-116. 
Jacques, Guillaume. 2013. Derivational morphology in Khaling. In Li FangKuei Society for Chinese Linguistics, Young Scholar Symposium, University of Washington at Seattle.

Jacques, Guillaume, Aimée Lahaussois, Boyd Michailovsky \& Dhan Bahadur Rai. 2012. An overview of Khaling verbal morphology. Language and linguistics 13.6. 1095-1170.

Michailovsky, Boyd. 1975. Notes on the Kiranti verb (East Nepal). Linguistics of the Tibeto Burman Area 2.2. 183-217.

Michailovsky, Boyd. 1994. Manner vs place of articulation in the Kiranti initial stops. In Hajime Kitamura, Tatsuo Nishida \& Nagano Yasuhiko (eds.), Current Issues in Sino-Tibetan Linguistics, Osaka: National Museum of Ethnology.

Michailovsky, Boyd. 2002. Limbu-English Dictionary. Kathmandu: Mandala Book Point.

Michailovsky, Boyd. 2012. Internal reconstruction of the Dumi verb : Lexical bases and stem formation. Linguistics of the Tibeto-Burman Area 35.2. 49-87.

Opgenort, Jean-Robert. 2005. A grammar of Jero, with a historical comparative study of the Kiranti languages. Leiden: Brill.

Opgenort, Jean-Robert. 2011. A note on Tilung and its position within Kiranti. Himalayan Linguistics 10.1. 253-271.

Rai, Netramani. 2011. Dumi-Nepali-English dictionary. Baksila: Dumi Kirat Rai Phansikim.

Starostin, Sergei A. 1994-2000. Proto-Kiranti reconstruction (online database). http://starling.rinet.ru/.

Walther, Géraldine, Guillaume Jacques \& Benoît Sagot. 2014. The OpacityCompactness Tradeoff: Morphomic Features for an Economical Account of Khaling Verbal Inflection. In 16th International Morphology Meeting, Budapest. 